\section{Práticas de apoio das avós à amamentação: revisão integrativa}

\section{Breastfeeding support provided by grandmothers: an integrative review}

Bárbara Helena de Brito Angelo 1

Cleide Maria Pontes 2

Luciana Pedrosa Leal 3

Márcia de Souza Gomes 4

Thais de Almeida da Silva 5

Maria Gorete Lucena de Vasconcelos 6

1,2,3,5,6 Programa de Pós-Graduação em Enfermagem. Departamento de Enfermagem. Centro de Ciências da Saúde. Universidade Federal de Pernambuco. Av. Prof. Moraes Rego, s.n. $2^{\circ}$ piso do bloco A, anexo ao Hospital das Clínicas/UFPE. Cidade Universitária. Recife, PE, Brasil. CEP 50670-901. E-mail: enfabarbarabrito@hotmail.com

4 Universidade Federal de Pernambuco. Recife, PE, Brasil.

\section{Resumo}

Objetivos: investigar as práticas das avós de apoio à amamentação.

Métodos: esta revisão integrativa buscou responder a seguinte questão norteadora: "Quais as práticas das avós de apoio à amamentação?". Com o cruzamento dos descritores "rede social", "aleitamento materno" e "relações familiares", em agosto de 2012, nas bases de dados: National Library of Medicine (Medline), Literatura Latino-Americana e do Caribe em Ciências da Saúde (Lilacs), Base de Datos de Enfermería em Español (CUIDEN), Repositório Científico de Acesso Aberto de Portugal (RCAAP), Base de Dados de Enfermagem (BDENF), Revisões Sistemáticas da Colaboração Cochrane (Cochrane) e na biblioteca virtual Scientific Electronic Library Online (SciELO), 4092 artigos foram encontrados. Após a aplicação dos critérios de inclusão e exclusão, 20 artigos compuseram a amostra do estudo. Os resultados dos estudos foram agrupados por similaridade temática.

Resultados: as avós reconhecem a importância do aleitamento materno; representam um modelo a ser seguido; auxiliam nos afazeres domésticos e na prestação de cuidados; fornecem informações e, por vezes, desestimulam o aleitamento materno.

Conclusões: as práticas de apoio das avós são influenciadas por suas próprias experiências e pelo contexto sociocultural que estão inseridas.

Palavras-chave Aleitamento materno, Educação em enfermagem, Rede social, Relações familiares 


\section{Introdução}

Apesar dos benefícios do aleitamento materno, amamentar não é uma prática adotada universalmente. Evidências sustentam que o aleitamento artificial é tão antigo quanto a história da civilização e que o valor atribuído ao leite materno e às suas vantagens nutricionais e afetivas apresentam flutuações ao longo da história em diferentes sociedades. ${ }^{1}$

Ao longo dos anos a prática da amamentação recebeu influências sociais, econômicas e culturais em decorrência da incorporação de costumes pela sociedade. Logo, esta questão revela que a amamentação não é instintiva nem automática, é uma ação que está fundamentada na subjetividade e na vivência das mulheres, sendo condicionada pelo contexto social, bem como pela rede social da nutriz, especialmente por sua mãe. ${ }^{2}$

Ao se analisar a rede social da nutriz, observa-se que o papel das avós se sobressai no auxílio com as atividades domésticas e cuidados com a criança, permanência ao lado da lactante, oferta de uma palavra de apoio e no compartilhamento de informações e conselhos. Essas práticas apoiadoras são agrupadas em um dos cinco tipos de apoio: presencial, emocional, informativo, instrumental e autoapoio, os quais podem ser positivos ou negativos de acordo com as experiências das próprias avós. ${ }^{3}$

Estas experiências foram influenciadas, em décadas anteriores, pelas indústrias de alimento infantil através da comercialização e disseminação da utilização de fórmulas lácteas nos meios de comunicação. As mães não acreditavam na capacidade de ter leite "suficiente" para o bebê ou produzir leite com qualidade, por considerá-lo "ralo e fraco", reduzindo a credibilidade do aleitamento materno. Isto ocorreu notadamente a partir da década de 1930 e até hoje repercute nas ações dessas mulheres-avós de apoio e estímulo à amamentação. ${ }^{2}$

Portanto, apoiar as mulheres para amamentarem seus filhos significa ir além das explicações sobre as vantagens dessa prática e das orientações sobre as técnicas de amamentação. Para compreensão do fenômeno da amamentação se faz necessário buscar a intencionalidade da mulher frente ao ato de amamentar no cenário das suas ações cotidianas e nas múltiplas relações estabelecidas no âmbito da rede social que a cerca, incluindo o apoio recebido da sua mãe. 4

Assim, reconhecendo a importância de estudar as ações apoiadoras ou não das avós no processo da amamentação e a temporalidade dessas ações, o objetivo deste estudo é investigar a produção cientí- fica sobre a temática em uma década, com a finalidade de agrupar o conhecimento produzido para o embasamento de práticas baseadas em evidências.

\section{Métodos}

O estudo é uma revisão integrativa, definida como um método amplo cujos estudos incluídos são analisados de forma ordenada e abrangente em relação aos seus objetivos, materiais e métodos, permitindo que o leitor analise o conhecimento préexistente sobre o tema investigado. 5

Para tanto, procederam-se as seguintes etapas: identificação do problema, formulação da questão norteadora, seleção da amostra, categorização e análise dos dados, discussão dos resultados e síntese do conhecimento. 6

Para a coleta dos dados utilizou-se a seguinte questão norteadora: "Quais as práticas de apoio das avós à amamentação?" Para o levantamento dos dados, dois revisores independentes consultaram as seguintes bases: National Library of Medicine, Bethesda, MD (Medline), Literatura LatinoAmericana e do Caribe em Ciências da Saúde (Lilacs), Base de Datos de Enfermería em Español (CUIDEN), Repositório Científico de Acesso Aberto de Portugal (RCAAP), Base de Dados de Enfermagem (BDENF), Revisões Sistemáticas da Colaboração Cochrane (Cochrane) e na biblioteca virtual Scientific Electronic Library Online (SciELO). Adotaram-se os descritores e suas combinações nas línguas portuguesa, inglesa e espanhola a seguir: "rede social", "aleitamento materno" e "relações familiares". Inicialmente utilizou-se a busca pelos descritores individualmente, posteriormente foram cruzados aos pares e finalmente foi feita a integração dos três descritores.

Após o cruzamento dos pares e do trio de descritores foram localizados 4092 artigos, aos quais foram aplicados os seguintes critérios de inclusão: idiomas já descritos, publicação entre 2002 e 2012 e abordagem da avó no contexto do aleitamento materno. Foram excluídos editoriais, cartas ao editor, estudos reflexivos, revisões integrativas e revisões sistemáticas, trabalhos de conclusão de curso. Os artigos encontrados em mais de uma base de dados foram catalogados uma única vez, obedecendo à seguinte ordem: Medline, Lilacs, BDENF, SciELO, RCAAP. (Tabela 1).

Após verificar a adequação perante os critérios de inclusão e exclusão, 273 artigos foram selecionados para a leitura dos resumos. Destes, 31 contemplavam as avós no contexto da amamentação. 
Resultado do cruzamento dos descritores por base de dados. Recife-PE, 2012.

\begin{tabular}{|c|c|c|c|c|c|c|c|c|}
\hline Descritores & Lilacs & Scielo & BDENF & Medline & CUIDEN & Cochrane & RCAAP & Total \\
\hline $\begin{array}{l}\text { Amamentação and } \\
\text { Rede de apoio }\end{array}$ & 19 & 06 & 00 & 784 & - & - & 96 & 905 \\
\hline $\begin{array}{l}\text { Amamentação and } \\
\text { Relações familiares }\end{array}$ & 20 & 06 & 62 & 71 & - & - & 37 & 196 \\
\hline $\begin{array}{l}\text { Rede de apoio and } \\
\text { Relações familiares }\end{array}$ & 36 & 31 & - & 840 & - & - & 2053 & 2960 \\
\hline $\begin{array}{l}\text { Amamentação and } \\
\text { Rede de apoio and } \\
\text { Relações familiares }\end{array}$ & 01 & - & - & 05 & - & - & 25 & 31 \\
\hline Total incluído & 76 & 43 & 62 & 916 & - & - & 2115 & 4092 \\
\hline
\end{tabular}

Lilacs= Literatura Latino-Americana e do Caribe em Ciências da Saúde; SciELO= Scientific Electronic Library Online; BDENF= Base de Dados de Enfermagem; Medline= National Library of Medicine; CUIDEN= Base de Datos de Enfermería em Español; Cochrane= Revisões Sistemáticas da Colaboração Cochrane; RCAAP= Repositório Científico de Acesso Aberto de Portugal.

Dessa forma, procedeu-se a leitura completa dos 31 artigos, a qual revelou que apenas 21 deles respondiam satisfatoriamente à questão norteadora.

Para avaliar o rigor metodológico dos estudos incluídos foi utilizado o Critical Appraisal Skills Programme (CASP), ${ }^{7}$ instrumento composto por dez questões que abordam os seguintes critérios: clareza na identificação dos objetivos da pesquisa, adequação da metodologia empregada, tipo de estudo, recrutamento dos participantes, coleta de dados, relação pesquisador e participante, aspectos éticos, análise dos dados, resultados e contribuições da pesquisa. Um artigo foi excluído nessa etapa por contemplar abaixo de $60 \%$ dos critérios. Portanto, 20 artigos compuseram a amostra. A Figura 1 mostra o fluxograma das etapas empregadas na seleção dos estudos.

Para o registro e organização das informações dos estudos selecionados, foi elaborado um instrumento contendo: registro do título, autor, ano e país de publicação, idioma, base de dados, objetivos, delineamento metodológico, práticas das avós de apoio à amamentação e nível de evidência Stetler et al.8: nível I - resultado de metanálise de estudos clínicos controlados e randomizados; nível II estudo de desenho experimental; nível III - pesquisas de desenho quase-experimentais; nível IV - estudos qualitativos ou estudos descritivos; nível V relatórios de casos ou relatos de experiências; nível VI - opiniões de especialistas ou com base em normas ou legislação.

Em continuidade, as práticas das avós foram agrupadas em categorias, mediante a técnica de análise temática9: 1- Reconhecendo a importância do aleitamento materno; 2- A avó que amamentou: um modelo a ser seguido; 3-Participação na maternidade das filhas; 4- Auxílio nos afazeres domésticos e na prestação de cuidados; 5 - As avós como fonte de informações e 6- Desestimulando o aleitamento materno. Alguns artigos foram inseridos em mais de uma categoria temática, uma vez que os autores analisaram a rede social da puérpera em diversos cenários. 
Figura 1

Fluxograma das etapas empregadas na seleção da amostra. Recife-PE, 2012.
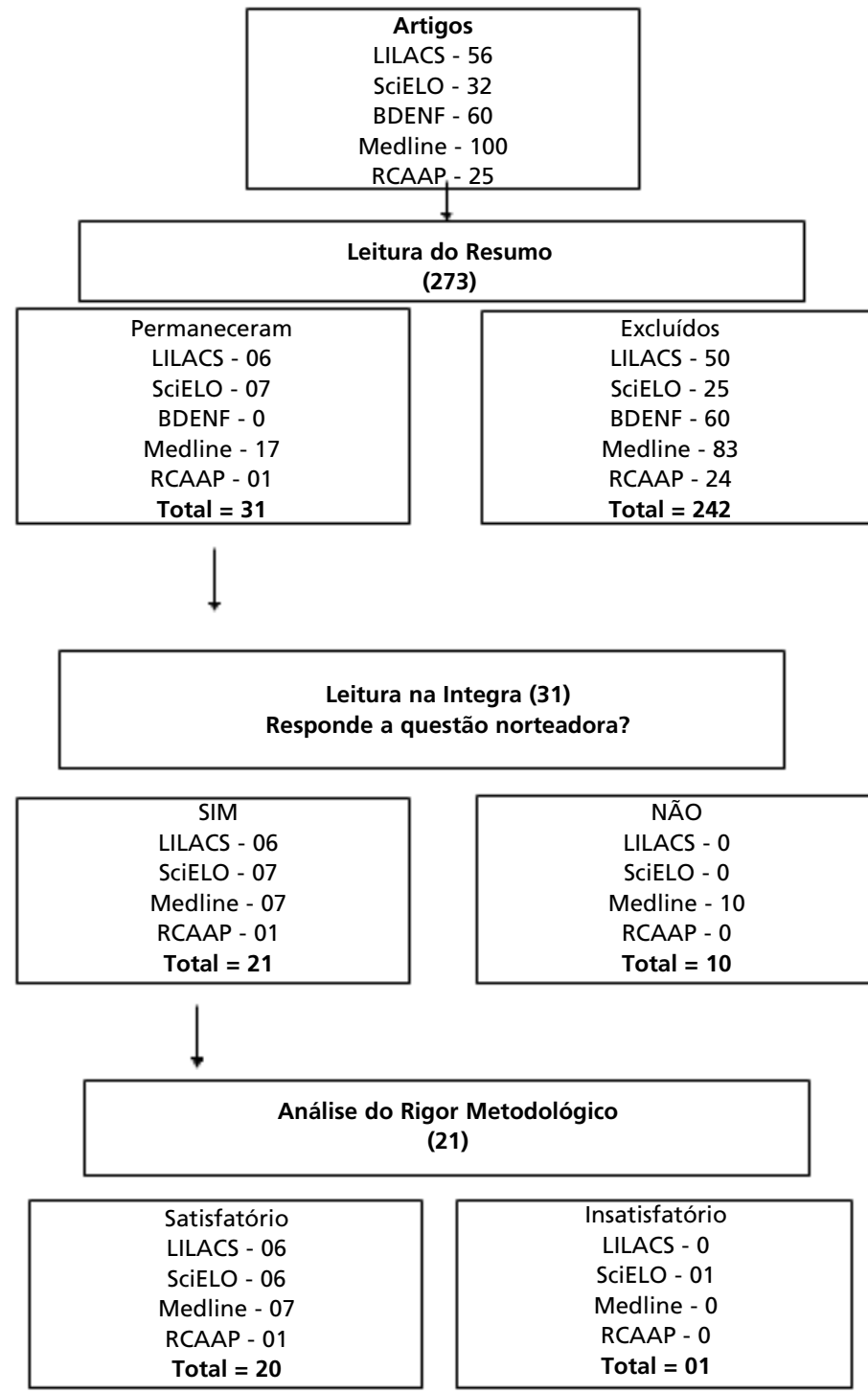

Lilacs= Literatura Latino-Americana e do Caribe em Ciências da Saúde; SciELO= Scientific Electronic Library Online; BDENF= Base de Dados de Enfermagem; Medline= National Library of Medicine; RCAAP= Repositório Científico de Acesso Aberto de Portugal. 


\section{Resultados}

Em relação ao delineamento da pesquisa, foram identificados: seis estudos com abordagem quantitativa e delineamento não experimental10-15 e 14 estudos com abordagem qualitativa, $16-29$ todos com nível de evidência IV.10-29 A amostra final desta revisão foi constituída por 20 artigos publicados entre 2003 e 2011

Os estudos foram publicados em sua maioria no Brasil,13,15-21,23,25-28 seguidos da Inglaterra11,12,29 e Estados Unidos, 10-24 três e dois, respectivamente, tendo a Austrália 22 e Holanda 14 um artigo cada. No que concerne à autoria das publicações, enfermeiros foram os autores principais em 13 artigos analisados, 14,21-23,25-26,28-29 médicos11,15 e nutri- cionistas 13,27 em duas publicações e em três não foi possível identificar a formação. 10,12,24 Em relação aos sujeitos pesquisados, 14 enfocaram as nutrizes;10-17,21,24-26,28-29 quatro as mães 19-20,22-23 e dois contemplaram ambas. ${ }^{18,27}$ Dentre os estudos, oito foram publicados em periódicos de Enfermagem;13,18-19,21,23,25,28-29 sete em revistas contemplando a área materno-infantil10-12,14,17,22,24 e dois convergiram para a área interdisciplinar. 16,26 Além destas, revistas sobre gerontologia, ${ }^{20}$ saúde coletiva 27 e saúde pública 15 contribuíram com uma publicação cada uma (Tabela 2).

As práticas das avós estão apresentadas de acordo com as categorias que emergiram por similaridade temática. (Tabela 3).

Tabela 2

Caracterização dos artigos sobre as práticas de apoio das avós à amamentação. Recife-PE, 2012.

\begin{tabular}{lll}
\hline $\begin{array}{c}\text { Autor, local, } \\
\text { ano/rigor } \\
\text { metodológico* }\end{array}$ & $\begin{array}{c}\text { Abordagem } \\
\text { metodológica/nível } \\
\text { de evidência (NE) }\end{array}$ & Desenho do estudo \\
\hline Ekstro et al.10 & $\begin{array}{l}\text { Quantitativo, Não- } \\
\text { experimental/NE IV }\end{array}$ & $\begin{array}{l}\text { Estudo transversal realizado em Skaraborg, Suéca, com 194 } \\
\text { primíparas e 294 multíparas cujos filhos tinham entre nove e 12 } \\
\text { meses. Foram aplicados questionários sobre sentimentos de } \\
\text { Estados Unidos, 2003/100 }\end{array}$ \\
& confiança e apoio ao AM.
\end{tabular}

Ludvigsson JF11

Inglaterra, 2003/100

Olayemi $O$ et al.12

Inglaterra, 2007/100

Carvalhães et al.13

Brasil, 2007/100

Lu $\mathrm{H}$ et al. 14

Holanda, 2011/100

Susin et al. 15

Brasil, 2005/100

Ichisato e Shimo ${ }^{16}$

Brasil, 2006/100
Quantitativo, Nãoexperimental/NE IV

Quantitativo, Nãoexperimental/NE IV

Quantitativo, Nãoexperimental/NE IV

Quantitativo, Nãoexperimental/NE IV

Quantitativo, Nãoexperimental/NE IV

Qualitativo/NE IV
Estudo transversal realizado em La Paz, Bolívia, com 518 mães e filhos menores de um ano. Foram aplicados questionários sobre AM e atitudes familiares.

Estudo tranversal realizado em Ibadan, Nigéria, com 602 mães de crianças entre seis e 12 meses. Foram aplicados questionários sobre sua personalidade e duração, atitudes e experiências sobre o AM.

Estudo transversal realizado em Botucatu, São Paulo, com 380 mães de crianças menores de quatro meses em Campanha de Multivacinação para identificar os fatores associados ao AM exclusivo.

Estudo transversal realizado em Pequim e Yinchuan, China, com 214 primíparas e filhos de quatro meses. Utilizou-se uma escala sobre AM e o comportamento das mães em relação à família.

Estudo prospectivo realizado em Porto Alegre, Rio Grande do Sul, com 601 mães de recém-nascidos. Foram aplicados questionários sobre as práticas de alimentação da criança e a atuação das avós durante a o AM no primeiro, segundo, quarto e sexto mês pósparto.

Estudo exploratório/descritivo, realizado em Ribeirão Preto, São Paulo, com 12 lactantes mediante entrevista semiestruturada para identificar os fundamentos do senso comum referidos como suporte ao uso de lactogogos durante o AM. 
Caracterização dos artigos sobre as práticas de apoio das avós à amamentação. Recife-PE, 2012.

\begin{tabular}{|c|c|c|}
\hline $\begin{array}{l}\text { Autor, local, } \\
\text { ano/rigor } \\
\text { metodológico* }\end{array}$ & $\begin{array}{l}\text { Abordagem } \\
\text { metodológica/nível } \\
\text { de evidência (NE) }\end{array}$ & Desenho do estudo \\
\hline Bosi e Machado17 & Qualitativo/NE IV & Estudo de investigação social, realizado em Fortaleza, Ceará, com \\
\hline Brasil, 2008/90 & & $\begin{array}{l}13 \text { lactantes, com enfoque crítico-interpretativo mediante } \\
\text { entrevista individual em profundidade sobre as experiências das } \\
\text { mulheres que amamentam exclusivamente por seis meses. }\end{array}$ \\
\hline
\end{tabular}

Machado et al.18

Qualitativo/NE IV

Brasil, 2004/100

Teixeira MA e

Nitschke RG19

Brasil, 2008/70

Teixeira et al.20

Brasil, 2011/80

Gross FM et al.21

Brasil, 2011/100

Reid et al.22

Austrália, 2010/90

Teixeira et al.23

Brasil, 2006/100

Brown e Lee24

Estados Unidos, 2011/100

Muller e Silva25

Brasil, 2009/100

Zanin e Shacker26

Brasil, 2010/100
Qualitativo/NE IV

Qualitativo/NE IV

Qualitativo/NE IV

Qualitativo/NE IV

Qualitativo/NE IV

Qualitativo/NE IV

Qualitativo/NE IV

Qualitativo/NE IV
Estudo descritivo realizado em Uberaba, Minas Gerais, com dez mulheres, cinco nutrizes primíparas, no período de um a seis meses pós-parto, e suas respectivas mães mediante entrevista semiestruturada, procurando identificar o significado das vivências do processo de AM e sua reprodução através de gerações.

Estudo de interação e reflexão realizado em Florianópolis, Santa Catarina, sobre a implementação do modelo de cuidar em enfermagem junto a três mulheres-avós que vivenciavam em suas famílias o processo de AM. Foi desenvolvido em encontros individuais e grupais numa unidade de alojamento conjunto e nos domicílios.

Estudo descritivo realizado em Florianópolis, Santa Catarina, com três mulheres-avós mediante entrevista semiestruturada seguida de encontro em grupo sobre a implementação do Modelo de Cuidar em Enfermagem durante o processo de AM.

Estudo descritivo realizado em Palmeira das Missões, Rio Grande do Sul, com 11 primíparas, usuárias do Sistema Único de Saúde, mediante entrevista semiestruturada sobre as orientações recebidas por sua mãe e sogra a respeito Do AM e seus sentimentos frente a essas orientações.

Estudo descritivo, realizado em Sydney, Austrália, com 11 avós, sobre seu papel no apoio a novas famílias e a influência nas decisões sobre alimentação infantil.

Estudo descritivo, realizado em Florianópolis, Santa Catarina, com um avô e dez avós mediante entrevista semiestruturada e observação participante durante uma oficina, sobre a vivência com a prática do AM.

Estudo descritivo realizado no Reino Unido, com 33 mulheres com crianças de seis a 12 meses que mamaram exclusivamente até o $6^{\circ}$ mês, sobre motivação e experiências durante o AM.

Estudo descritivo realizado em Butantã, São Paulo, com 14 mulheres com filhos de até seis meses de idade, mediante entrevista semiestruturada, para identificar suas percepções sobre o apoio recebido para amamentar.

Estudo exploratório e descritivo, realizado em Vale do Sinos, Rio Grande do Sul, com seis mulheres primíparas, mediante entrevista semiestruturada sobre a participação das avós maternas durante o AM. 
Caracterização dos artigos sobre as práticas de apoio das avós à amamentação. Recife-PE, 2012.

\begin{tabular}{lll}
\hline $\begin{array}{c}\text { Autor, local, } \\
\text { ano/rigor } \\
\text { metodológico* }\end{array}$ & $\begin{array}{c}\text { Abordagem } \\
\text { metodológica/nível } \\
\text { de evidência (NE) }\end{array}$ & \multicolumn{1}{c}{ Desenho do estudo } \\
\hline $\begin{array}{l}\text { Marques et al.27 } \\
\text { Brasil, 2010/80 }\end{array}$ & Qualitativo/NE IV & $\begin{array}{l}\text { Estudo descritivo e exploratório, realizado em Coimbra, Minas } \\
\text { Gerais, com mães (58), pais (27) e avós (31) de crianças até dois } \\
\text { anos, mediante entrevistas semiestruturadas sobre o cotidiano de } \\
\text { todos esses atores durante o período de puerpério e lactação. }\end{array}$ \\
Souza et al.28 & $\begin{array}{l}\text { Estudo descritivo realizado no Rio de Janeiro, com 20 mulheres } \\
\text { com filhos menores de seis meses, mediante elaboração de mapa } \\
\text { Brasil, 2009/90 }\end{array}$ & $\begin{array}{l}\text { de rede social sobre pessoas que estavam presentes em suas vidas } \\
\text { durante o AM. }\end{array}$ \\
Estudo descritivo realizado em Hong Kong, com 17 mulheres que \\
Tarrant et al.29
\end{tabular}

*Percentagem de itens respondidos do Critical Appraisal Skills Programme; $\mathrm{AM}=$ aleitamento materno.

Tabela 3

Síntese das práticas das avós relacionadas à amamentação. Recife-PE, 2012.

Categorias Práticas das avós de apoio à amamentação

Reconhecendo a importância do aleitamento materno

A avó que amamentou: um modelo a ser seguido

Participação na maternidade das filhas

Auxílio nos afazeres domésticos e prestação de cuidados

As avós como fonte de informações

Desestimulando o aleitamento materno
Reconheceram os benefícios à criança;10,15-22 avós não conseguiram amamentar, mas expressaram desejo; 23 ajudaram outras mulheres a amamentar; 23 perceberam o aleitamento materno de forma positiva, demonstrando preocupação com o bem-estar do bebê;24 reconheceram o aleitamento como a maneira natural de alimentar a criança. 25

As nutrizes presenciaram a mãe amamentando; $16-19,20,25$ as nutrizes foram amamentadas 10,16

Transmitiram crenças e valores; 16 estreitaram o vínculo; 18 permaneceram junto; 18,26 reconciliaram-se; 11,18 lembraram os deveres e responsabilidades da filha; 18 forneceram orientações; 11,21 forneceram conforto21 e apoio emocional; 10,12,27 transmitiram segurança; 10,21,24 mantiveram atitudes positivas em relação à amamentação; 10 forneceram apoio frente às dificuldades; $13,14,20$ compartilharam hábitos e condutas 28

Arrumaram a casa;20,24 cozinharam;24,26 lavaram roupas;24 levaram as crianças mais velhas ao colégio; 24,26 auxiliaram na resolução de problemas físicos e psicológicos; 19 estimularam a ingestão de bons alimentos; 14 posicionaram a criança no peito; 24 deram banho; 20,24 cuidaram do coto umbilical;20,24 colocaram o bebê para eructar;25 levaram a criança ao colégio da filha para ser amamentada18

Orientaram frente à intercorrências e dificuldades;11,16,21 Ensinaram como dar o banho;21 ensinaram como cuidar da criança; 21 informaram sobre a necessidade de expor a mama a luz solar ou artificial;20 informaram sobre a necessidade de evitar a higienização a cada mamada; 21 orientaram não parar de ofertar o peito fissurado; ${ }^{11}$ orientaram sobre ingestão de determinados alimentos e água14,21

Desestimularam o aleitamento materno exclusivo, aconselhando o uso de água/ chás 11,21,15 e outros alimentos; 11,15 rejeitaram o leite materno como meio adequado para alimentar as crianças, desaconselhando o aleitamento14,17,22,29 e ofertando à criança água/chá e outros alimentos 13,21

*Percentagem de itens respondidos do Critical Appraisal Skills Programme; $\mathrm{AM}=$ aleitamento materno. 


\section{Discussão}

Por meio desta revisão foi constatado que a avó que amamentou representa um modelo a ser seguido, influenciando positivamente a adesão a tal prática. ${ }^{16-}$ 18,20,25 Em estudo realizado em Ribeirão Preto (SP) todas as mulheres relataram terem sido amamentadas, retratando a importância da história familiar e, dependendo do que tenha ocorrido e do que isso tenha significado, essa história se torna um aspecto valioso na decisão de amamentar. 16

A amamentação é permeada por mitos, crenças e valores repassados de geração em geração, influenciado pelo contexto histórico em que está inserida a nutriz, bem como pela sua rede social. Assim, as avós são consideradas elementos fundamentais para a manutenção ou abandono de tal prática. 30

No processo de incentivo à amamentação as avós reconhecem que o leite materno é um elemento fundamental para a saúde e o desenvolvimento do bebê, interferindo no processo de modo a estimular, promover, proteger e apoiar essa prática, 18 demonstrando preocupação com o neto 24 e dando suporte a outras mulheres para amamentar.23 A mãe da lactante é uma fonte de informações sobre os cuidados com a criança e com o corpo, fato que se torna mais relevante quando se considera que, durante o aleitamento materno, as mães encontram-se mais vulneráveis a pressões e aos conselhos/orientações de terceiros. 30

A permanência das mães junto às filhas no pósparto permite a transmissão de orientações sobre o cuidado com o corpo e com o recémnascido.11,14,16,21 Dentre os cuidados com o corpo, as avós forneceram informações sobre a exposição das mamas à luz, a não necessidade de higienizá-las a cada mamada e a importância de não interromper a oferta do peito fissurado. No puerpério, decorrente do maior convívio, é frequente o compartilhamento de crenças e valores de mãe para filha.

Os mitos geralmente estão relacionados à crença de leite ralo e fraco que não alimenta e, precisa ser complementado, à necessidade de ofertar água à criança nos dias quentes e à utilização de chás para aliviar possíveis cólicas no lactente. ${ }^{21}$ Os mitos que permeiam o imaginário desta avó serão responsáveis pelas orientações e valores transmitidos às suas filhas.

No compartilhamento de valores à nutriz, a mãe poderá transmitir, também, tabus e proibições inerentes a um dado contexto histórico-social.18 Em décadas anteriores, a mídia e profissionais de saúde influenciaram uma geração de mulheres que desacreditaram no leite materno como fonte exclusiva de alimento, havendo uma tendência ao repasse das informações adquiridas a essa nova geração. ${ }^{17}$

Estudo realizado na Suécia afirma que grande número de avós foram mães entre as décadas de 1960 e 1970 quando as taxas de aleitamento materno naquele país eram baixas, o que implica numa geração com pouca experiência sobre amamentação exclusiva, precisando superar lembranças desagradáveis de sua própria amamentação a fim de tornarem-se boas conselheiras. 10

As avós, quando adeptas da complementação, utilizam-se do argumento de que alimentaram seus filhos com leite artificial e atualmente eles estão vivos e saudáveis. Essas falas produzem na lactante insegurança quanto à melhor maneira de alimentar os lactentes e medo de fracassar no seu papel de mãe, com consequente abandono do aleitamento materno exclusivo. 26

Além da rejeição do leite materno como fonte adequada de alimento à criança e a contraindicação ao aleitamento exclusivo, o oferecimento de água, chás e outros alimentos tem sido frequentemente citados como ações de desestímulo à amamentação.11,13,15,17,21-22,28,29 Estudo realizado em Porto Alegre constatou que o fato de a avó recomendar água e/ou chás aumentou em duas vezes o risco para a criança não estar sendo amamentada exclusivamente no final do primeiro mês de vida. 15

De maneira antagônica, a África é um exemplo de país no qual as mães das lactantes são favoráveis à amamentação exclusiva e consideram desnecessária e nociva à saúde da criança a suplementação com água, ${ }^{31}$ sendo possível afirmar a existência de estudos nos quais predominam as práticas incentivadoras da amamentação. 10,12,16,19,23,24,26,27

Os benefícios oriundos da presença da avó na fase de lactação podem ser representados por estreitamento de vínculo, fornecimento de conforto e apoio emocional, transmissão de segurança, além de ser, por vezes, uma fase de reconciliação após conflitos ocorridos anteriormente entre mãe e filha. 12,13,18,28 Ainda durante esse período, as avós auxiliam nos afazeres domésticos, cuidando das crianças mais velhas e frequentemente atuam na prestação de cuidados ao lactente e à filha, permitindo que ela disponha de maior tempo para a amamentação. ${ }^{20,24,26}$

Ao caracterizar os estudos, ressalta-se ainda a representatividade numérica das publicações nacionais, o que parece estar relacionado ao movimento mundial para a reconstrução da cultura da amamentação. Nesse sentido, vem ganhando destaque no meio acadêmico a realização de pesquisas envolvendo a influência exercida pelas 
avós na amamentação, uma vez que os significados atribuídos pelas mulheres acerca de suas vivências no aleitamento materno reproduzem, em parte, os significados construídos por suas mães, estando estes fundamentados em experiências maternas anteriores. $3,10,14,16,20$

\section{Considerações finais}

O puerpério se caracteriza como um período de maior convívio entre as gerações, propiciando a transmissão de conhecimentos e o compartilhamento de experiências a respeito do aleitamento materno. É também nessa fase que as mães instruem as lactantes sobre os cuidados com o corpo e com o recémnascido.

Os resultados indicaram que a amamentação é uma prática aprendida, transmitida de mães para filhas e influenciada por fatores culturais. Neste sentido, reconhece-se a influência que as avós repre-

\section{Referências}

1. Bosi MLM, Machado MT. Amamentação: um resgate histórico. Escola de Saúde Pública do Ceará [periódico online]. 2005 [acesso em 11 set 2012]. 1(1): 9p. Disponível em: http://www.aleitamento.com/upload\%5Carquivos\% 5Carquivo1_1688.pdf

2. Souza MHN, Souza IEO, Tocantins FR. A utilização do referencial metodológico de rede social na assistência de enfermagem a mulheres que amamentam. Rev Latino-am Enfermagem. 2009; 17 (3): 354-60.

3. Sousa AM, Fracolli LA, Zoboli ELCP. Práticas familiares relacionadas à manutenção da amamentação: revisão da literatura e metassíntese. Rev Panam Salud Publica. 2013; 34 (2): 127-34.

4. Souza MHN, Souza IEO, Tocantins, FR. Abordagem da fenomenologia sociológica na investigação da mulher que amamenta. Rev Enferm UERJ. 2009; 17 (1): 1-5.

5. Pompeo DA, Rossi LA, Galvão CM. Integrative literature review: the initial step in the validation process of nursing diagnoses. Acta Paul Enferm. 2009; 22 (4): 1-4.

6. Whttemore R, Knaff $\mathrm{K}$. The integrative review: update methodology. J Adv Nurs. 2005; 52 (5): 546-53.

7. Critical Appraisal Skills Programme [homepage]. 1993 [acesso em 17 dez 2014]. Disponível em: http://www.caspuk.net/

8. Stetler CB, Morsi D, Rucki S, Broughton S, Corrigan B, Fitzgerald J, K Giuliano, Havener P, Sheridan EA. Utilization-focused integrative reviews in a nursing service. Appl Nurs Res. 1998; 11 (4): 195-206.

9. Bardin L. Trad. Luís Antero Reto e Augusto Pinheiro. Análise de conteúdo. Lisboa: Edições 70; 2011.

10. Ekstro A, Widstrom AM, Nissen E. Breastfeeding support from partners and grandmothers: perceptions of Swedish women. Birth. 2003; 30 (4): 261-6. sentam para o aleitamento materno alicerçada pelas suas próprias experiências e pelo contexto sociocultural em que estão inseridas. Essas experiências são decorrentes do conhecimento empírico acumulado ao longo da vida e habitualmente repassado às filhas durante o período pós-parto.

Para que haja diminuição do desmame precoce, é imprescindível que as mães das lactantes sejam lembradas pelos profissionais de saúde ao desenvolverem ações de educação em saúde na temática do aleitamento materno para que elas tornem-se auxiliadoras e incentivadoras da amamentação.

A exaustiva busca de artigos na literatura científica para compor a revisão integrativa demonstrou que a maioria das publicações utilizou-se da metodologia qualitativa, demonstrando a necessidade da realização de mais estudos que envolvam outros métodos, ampliando assim o conhecimento relativo à influência das avós na manutenção do aleitamento materno exclusivo.

11. Ludvigsson JF. Breastfeeding in Bolivia-Information and attitudes. BMC Pediatr. 2003. 3 (4): 1-12.

12. Olayemi O, Aimakhu CO, Bello FA, Motayo VO, Ogunleye AA, Odunukan OW, Ojengbede OA. The influence of social support on the duration of breast-feeding among antenatal patients in Ibadan. J Obstet Gynaecol. 27 (8): 802-

13. Carvalhães MABL, Parada CMG, Costa MP. Factors associated with exclusive breastfeeding in children under four months old in Botucatu-SP, Brazil. Rev Latino-Am Enferm. 2007; 15 (1): 62-9.

14. Lu H, Li H, Ma S, Xia L, Christensson K. Perceived family perceptions of breastfeeding and Chinese new mothers' breastfeeding behaviors. Sex Reprod Health. 2011; 2 (4): 143-7.

15. Susin LRO, Giugliani ERJ, Kummer SC. Influência das avós na prática do aleitamento materno. Rev Saúde Pública. 2005; 39 (2): 141-7.

16. Ichisato SMT, Shimo AKK. Vivência da amamentação: lactogogos e rede de suporte. Ciênc Cuidado Saúde. 2006; 5 (3): 355-62.

17. Bosi MLM, Machado MT. Compreendendo a prática do aleitamento exclusivo: um estudo junto a lactantes usuárias da rede de serviços em Fortaleza, Ceará, Brasil. Rev Bras Saúde Mater Infant. 2008; 8 (2): 187-196.

18. Machado ARM, Nakano MAS, Almeida AM, Mamede MV. O lugar da mãe na prática da amamentação de sua filha nutriz: o estar junto. Rev Bras Enferm. 2004; 57 (2): 183-7.

19. Teixeira MA, Nitschke RG. Modelo de cuidar em enfermagem junto às mulheres-avós e sua família no cotidiano do processo de amamentação. Texto Contexto-Enferm. 2008; 17 (1): 183-91. 
20. Teixeira MA, Nitschke RG, Silva LWS. A prática da amamentação no cotidiano familiar - um contexto intergeracional: influência das mulheres-avós. Rev Temática Kairós Gerontol. 2011; 14 (3): 205-21. Disponível em:http://revistas.pucsp.br/index.php/kairos/article/view/65 01

21. Gross FM, Vander Sand IC, Girardon-Perlini NMO, Cabral FB. Influence of grandmothers on infant feeding: what they say to their daughters and granddaughters. Acta Paul Enferm. 2011; 24 (4): 534-40.

22. Reid J, Schmied V, Beale B. I only give advice if I am asked': examining the grandmother's potential to influence infant feeding decisions and parenting practices of new mothers. Women Birth. 2010; 23 (2): 74-80.

23. Teixeira MA, Nitschke RG, De Gasperi P, Siedler MJ Significados de avós sobre a prática do aleitamento materno no cotidiano familiar: a cultura do querer-poder amamentar. Texto Contexto-Enferm. 2006; 15 (1): 98-106.

24. Brown A, Lee Michelle. An exploration of the attitudes and experiences of mothers in the United Kingdom who chose to breastfeed exclusively for 6 months postpartum. Breastfeed Med. 2011; 6 (4): 197-204.

25. Muller FS, Silva IA. Representações sociais de um grupo de mulheres/nutrizes sobre o apoio à amamentação. Rev Latino-am Enferm. 2009; 17 (5): 651-7.

Recebido em 1 de julho de 2014

Versão final apresentada em 30 de janeiro de 2015

Aprovado em 24 de março de 2015
26. Zanin LC, Shacker LC. Avós maternas: incentivadoras da amamentação? Rev Conhecimento Online. 2010. 2 (1): 12p. Disponível em: http://www.feevale.br/site/files/documentos/pdf/35211.pdf

27. Marques ES, Cotta RMM, Botelho MIV, Frannceschini SCC, Araújo RMA, Lopes LL. Rede social: desvendando a teia de relações interpessoais da nutriz. Physis. 2010. 20 (1): 19p. Disponível em: http://www.scielo.br/scielo.php? script=sci_arttext\&pid=S0103-73312010000100014

28. Souza MHN, Souza IEO, Tocantins FR. The use of social network methodological framework in nursing care to breastfeeding women. Rev Latino-Am Enferm. 2009; 17 (3): 354-60.

29. Tarrant M, Dodgson JE, Kay VCW. Becoming a role model: the breastfeeding trajectory of Hong Kong women breastfeeding longer than 6 months. Int J Nurs Stud. 2004; 41(5): $535-46$

30. Marques ES, Cotta RMM, Magalhães KA, Sant'Ana LFR, Gomes AP, Siqueira-Batista R. A influência da rede social da nutriz no aleitamento materno. Ciênc Saúde Coletiva. 2010; 15 (Supl. 1): 1391-1400.

31. Almroth S, Mohale M, Latham MC. Unnecessary water supplementation for babies: grandmothers blame clinics. Acta Pediatr. 2000; 89 (12): 1408-13. 